Article

\title{
Leaf Extract Arbitrated Biogenic Synthesis of Silver Nanospheres by a Medicinal Plant from the Western Ghats with Enhanced Antimicrobial Property
}

\author{
John Sherin ${ }^{1}$, Puvanesvaran Senthil Kumar ${ }^{2}$ and Swaminathan Karuthapandian $2, * \mathbb{D}$ \\ 1 Department of Chemistry, Sri Kaliswari College (Autonomous), Sivakasi 626130, Tamilnadu, India; \\ jsherin1986@gmail.com \\ 2 Department of Chemistry, VHNSN College (Autonomous), Virudhunagar 626001, Tamilnadu, India; \\ senthilkumar.p@vhnsnc.edu.in \\ * Correspondence: karuthapandian@vhnsnc.edu.in; Tel.: +91-94-8628-7223
}

Citation: Sherin, J.; Senthil Kumar, P.; Karuthapandian, S. Leaf Extract Arbitrated Biogenic Synthesis of Silver Nanospheres by a Medicinal Plant from the Western Ghats with Enhanced Antimicrobial Property. Photochem 2021, 1, 264-274. https:// doi.org/10.3390/photochem1020016

Academic Editor: Massimo La Deda

Received: 6 August 2021

Accepted: 1 September 2021

Published: 6 September 2021

Publisher's Note: MDPI stays neutral with regard to jurisdictional claims in published maps and institutional affiliations.

Copyright: (C) 2021 by the authors. Licensee MDPI, Basel, Switzerland. This article is an open access article distributed under the terms and conditions of the Creative Commons Attribution (CC BY) license (https:// creativecommons.org/licenses/by/ $4.0 /)$.

\begin{abstract}
In the present study, we report the greener, simple, cost effective, non-hazardous and ecofriendly synthesis of silver (Ag) nanoparticles from Alstonia scholaris (L.) R. Br. for the first time. The synthesis of silver nanoparticles using the leaf stock acted as a reducing as well as the capping agent simultaneously. The bio-reduced silver nanoparticles were characterized using ultra violetvisible spectroscopy (UV) exhibiting blue shift absorption peak in the region $440 \mathrm{~nm}$. The newly synthesized Ag NPs were sphere-like in structure and grew well with a crystalline size of $16.57 \mathrm{~nm}$. The Fourier transform infrared (FT-IR) analysis identifies the biomolecules which are involved during the synthesis process. The synthesized nanocatalyst served as a good catalyst for degrading methyl orange dye under solar light irradiation and was monitored spectrophotometrically. Furthermore, the antimicrobial potential of Ag NPs was evaluated an could competently inhibit different pathogenic organisms, including bacteria and fungi. Additionally, the efficiency of the silver nanoparticles was tested against the photocatalytic degradation of methyl orange dye pollutant. Different operational parameters such as catalyst weight dosage, dye concentration and different $\mathrm{pH}$ were optimized. The pollutants were degraded within $35 \mathrm{~min}$. The present research work opens a pathway to synthesize nanomaterial by applying the principles of green chemistry.
\end{abstract}

Keywords: Alstonia scholaris; green synthesis; characterization; microbial activity

\section{Introduction}

To protect our inclusive environment, research workers compensated much interest in green nanotechnology and synthesis of nanomaterials using greener methods. In the various developing fields of green nanotechnology research, the plant products achieved an extensive range of applications in the field such as catalysis, sensors, solar cells and medicinal fields [1-4]. In contemporary research, nanoparticles are synthesized by different plants using active fields of interdisciplinary investigation (nanobiotechnology). Synthesizing nanoparticles was found compatible with environmentally benevolent materials rather than chemicals, under various conditions. Noble metals like gold, silver, platinum with well-defined shape, size and composition have applications in the areas of optics, electronics, sensors, catalysis, environmental, biotechnology, antibacterial activity, medicines, electronics, biology and biomedical applications, material science, physics, environmental remediation fields possessing various properties [5-8].

Among the noble metals, Ag NPs have a proliferating function in the medical field, because of their antimicrobial characteristic which is particularly helpful in eliminating viruses, bacteria and fungus to prevent the wide spread of diseases. Silver ion is considered as a soft acid and so it reacts with the soft base containing sulphur and phosphorous in the cell leading to cell death. Ag NPs also found use in the day-to-day applications due 
to their unique properties. Few include consumer products such as detergents, soaps, shampoo, house cleansing chemicals, transfer of heat to fuel tanks, food covering sheets, cans for storing the beverages and food $[9,10]$. The electrical conductivity of the Ag NPs increased the remedial properties offered for various illnesses including ointments for protecting against wounds, burns, anti-cancer agents, dental fillings, and additives in bone cement [11-14].

Compared to other biological alternatives against viruses, bacteria, yeast, fungi [15-18] for the green synthesis of Ag NPs, the most excellent choice is from plants. Plant extract paves a better route for the synthesis of nanoparticles which is a cost effective, eco-friendly benign method that required minimum or less sustenance, no essential use of any high pressure, energy, temperature, and toxic chemicals, being more advantageous over other methods [19]. The secondary metabolites present in the plants possess higher redox ability which could facilitate the biosynthesis of nanoparticles [20].

As far as we know, the information explained in the present work was a one-step greener synthesis of silver nanoparticles using Alstonia leaf extract which has not been reported hitherto. Hence, the facile greener approach of Ag NPs formation using Alstonia scholaris extract was reported for the first time. The photo degradation of methyl orange dye was studied using the synthesized Ag NPs. The antimicrobial efficacy of synthesized Ag NPs was evaluated using different pathogens which are active against an antibiotic resistant microorganism. The organic group present in the leaf reduces the silver nitrate solution from $\mathrm{Ag}^{+}$to $\mathrm{Ag}^{0}$ ions.

\section{Materials and Methods}

Analytical grade chemicals and reagents from Merck (Darmstadt, Germany) were used for the present study. Throughout the experiments deionized water was used. Unless otherwise noted, the reactions were performed at room temperature.

\subsection{Preparation of Plant Extract}

The leaves of Alstonia scholaris were collected from Courtallum hills, India. To remove junk, the fronds were washed several times with distilled water and dried in the absence of light. The dried leaves were homogenized by using a kitchen blender. In total, $5 \mathrm{~g}$ of homogenized powder of leaf was weighed and boiled with $100 \mathrm{~mL}$ sterilized water in a boiling water bath for $20 \mathrm{~min}$. The suspensions were filtered with Whatman filter paper No 1, collected and used for further examination.

\subsection{Biosynthesis of Silver Nanoparticles}

A total of $10 \mathrm{~mL}$ of aqueous leaf extracts of Alstonia scholaris was added to $250 \mathrm{~mL}$ Erlenmeyer flask containing $90 \mathrm{~mL}$ of $\mathrm{AgNO}_{3}(1 \mathrm{mM})$ solution and stirred vigorously at room temperature for $30 \mathrm{~min}$. Consequently, the color of the reaction mixture was changed from translucent yellow to a turbid brown color indicating the reduction of $\mathrm{Ag}^{+}$ ions. Furthermore, the formation of Ag nanoparticles was monitored using UV-visible spectroscopy (Shimadzu, Kyoto, Japan). The resulting reaction solution was washed several times with de-ionized water. The synthesized products obtained were centrifuged at $5000 \mathrm{rpm}$ for $30 \mathrm{~min}$, washed several times with de-ionized water and with ethanol. Finally, the particle was dried at $60^{\circ} \mathrm{C}$ and further targeted for potential for inhibition of antimicrobial agents against different pathogens.

\subsection{Characterization}

Surface morphology of the Ag nanospheres was studied using SEM with an (Model SUPRA 40 Scanning Electron Microscope, Max Planck, Müncheberg, Germany) acceleration voltage of $30 \mathrm{kV}$. The bulk morphology and particle size of Ag NPs were observed through transmission electron microscopy (TEM) using a Philips CM 200. X-ray diffraction (XRD) was performed to examine the crystal structure using a Philips PW-1710 X-ray 
diffractometer (Eindhoven, The Netherlands). Shimadzu UV Vis-1800 spectrometer and Shimadzu FTIR-8400 (Kyoto, Japan) was used to analyze the samples.

\section{Results and Discussion}

\subsection{UV Absorbance Analysis}

The fixed ratio of Alstonia scholaris leaf extract facilitated the metal ion solution to change the color from pale yellow to brown. The color change is due to the excitation of surface plasmon vibrations during the synthesis of nanoparticles. The surface plasmon resonance of silver nanoparticles produced an extinction band with the absorbance maximum nearer to $450 \mathrm{~nm}$ (Figure 1). The exciting colors of silver NPs transpired because the conduction electrons on the surface of every nanoparticle get vibrated when excited by light at a specific wavelength [21]. These vibrations resulted in tremendous bright colors that can be tuned by shifting the particle size and shape. Due to the collective interaction of the individual atoms with one another, the change in color took place [22]. The reduction of $\mathrm{Ag}^{+}$to $\mathrm{Ag}^{0}$ ions was completed within $30 \mathrm{~min}$ at room temperature, indicating the rapid pace and ease of this biosynthesis.

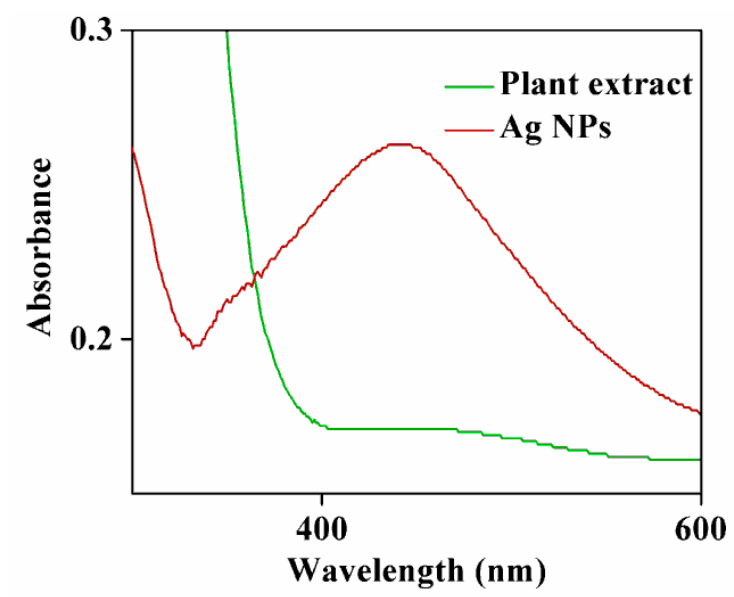

Figure 1. UV-visible absorbance spectrum of Ag nanoparticles.

\subsection{FTIR Analysis}

FTIR analysis was used to identify the capping ligands responsible for the bioreduction of silver nanoparticles present in the leaf extract. Figure 2 showed eminent IR bands were observed at 3428, 2927, 1604, 1373, and $1001 \mathrm{~cm}^{-1}$. The bands at $3428 \mathrm{~cm}^{-1}$ are due to the stretching vibration of $\mathrm{O}-\mathrm{H}$ group. The bands show a strong intensity due to $\mathrm{CH}$ stretching because of alkanes at $2927 \mathrm{~cm}^{-1}$. The peaks at $1604 \mathrm{~cm}^{-1}$ are medium due to $\mathrm{C}=\mathrm{O}$ stretching band and / or due to aromatic $\mathrm{C}=\mathrm{C}$ stretching vibration plane. The bands at $1373 \mathrm{~cm}^{-1}$ are assigned due to aliphatic $\left(-\mathrm{CH}_{2},-\mathrm{CH}_{3}\right)$ deformation. The $1001 \mathrm{~cm}^{-1}$ band may be due to the $\mathrm{C}-\mathrm{N}$ stretch due to aliphatic amines. Thus, O-H, C-H, N-H, C-N, alkanes which acted as stabilizing agents were responsible for the reduction of silver ions to silver nanoparticles [23].

\subsection{XRD Analysis}

XRD spectroscopy was used to explore the phase and crystalline nature of as synthesized Ag nanospheres as shown in Figure 3. The diffraction patterns of Ag nanospheres were indexed to cubic face and well matched with the standard JCPDS card no. 87-9722. The XRD patterns of as synthesized Ag nanospheres showed diffraction peaks in the $2 \theta$ regions of 38.05, 44.26 and 64.37 corresponding to the (111), (200) and (220) reflections of plane, respectively. The unassigned peaks may be due to the presence of a bioorganic substance in leaf extract that bound specifically on the surface of the Ag nanospheres. The crystallite size of the silver nanoparticles thus obtained, calculated using the Debye- 
Scherer's equation, was $16.57 \mathrm{~nm}$. Hence, the high crystalline nature of the synthesized Ag NPs was indisputably confirmed in the X-ray diffraction studies [24].

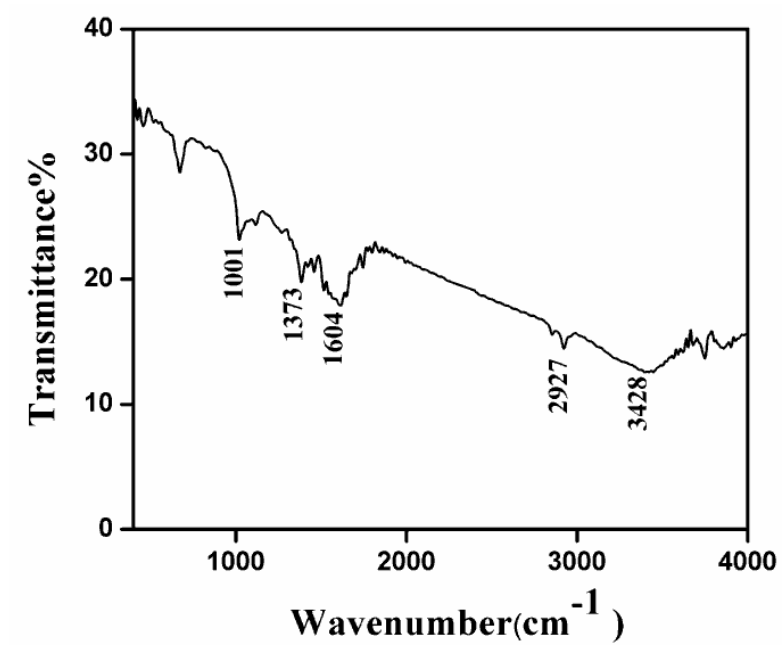

Figure 2. FTIR spectrum of as synthesized Ag nanoparticles.

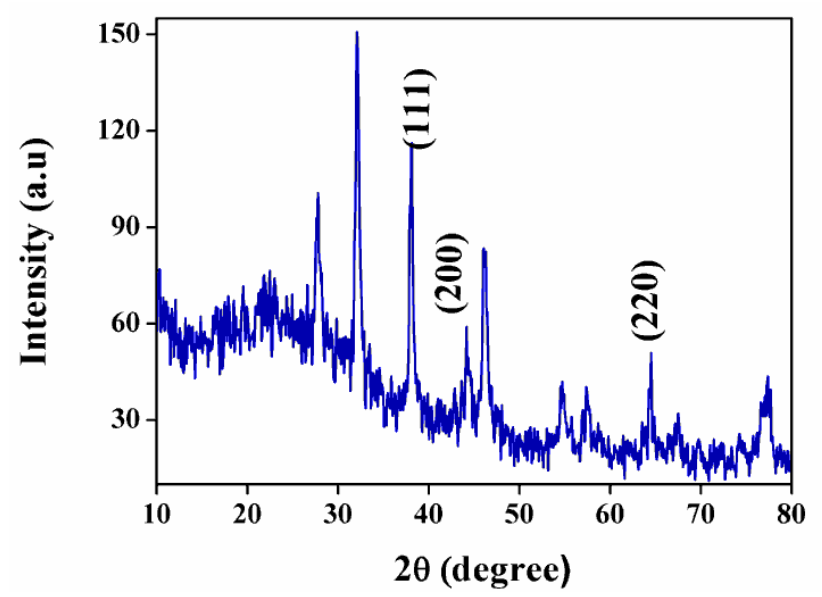

Figure 3. XRD pattern of as synthesized Ag nanoparticles.

\subsection{SEM and EDX Analysis}

SEM analysis was used to find out the morphology and surface nature of the Ag NPs synthesized which is shown in Figure 4. The SEM micrographs revealed that the Ag NPs synthesized were sphere-like in morphology and analyzed with different magnification. Generally, the shapes may be varied due to the usage of different quantities of leaf extract and reducing agent in the plant. The clusters of Ag nanoparticles were observed which may be due to the aggregation of their individual particles. The weight percentage of Ag present was $100 \%$ which was confirmed by EDX analysis, indicating the absence of any other impurities (Figure 5).

\subsection{TEM Analysis}

The size, structural and morphological prospect of the synthesized Ag NPs was examined using TEM analysis which is shown in Figure 6. TEM images showed nanoparticles are apparently spherical in shape with fairly smooth surface. An obvious assessment of the TEM images shows that the Ag NPs are bounded by an emaciated deposit of biomaterials of the plant extract. The images also showed the growth of Ag NPs and ensued preferentially on the (111) reflection plane. The variable sizes and shapes were noticed as spherical-like spheres and the particle size is $20 \mathrm{~nm}$. 


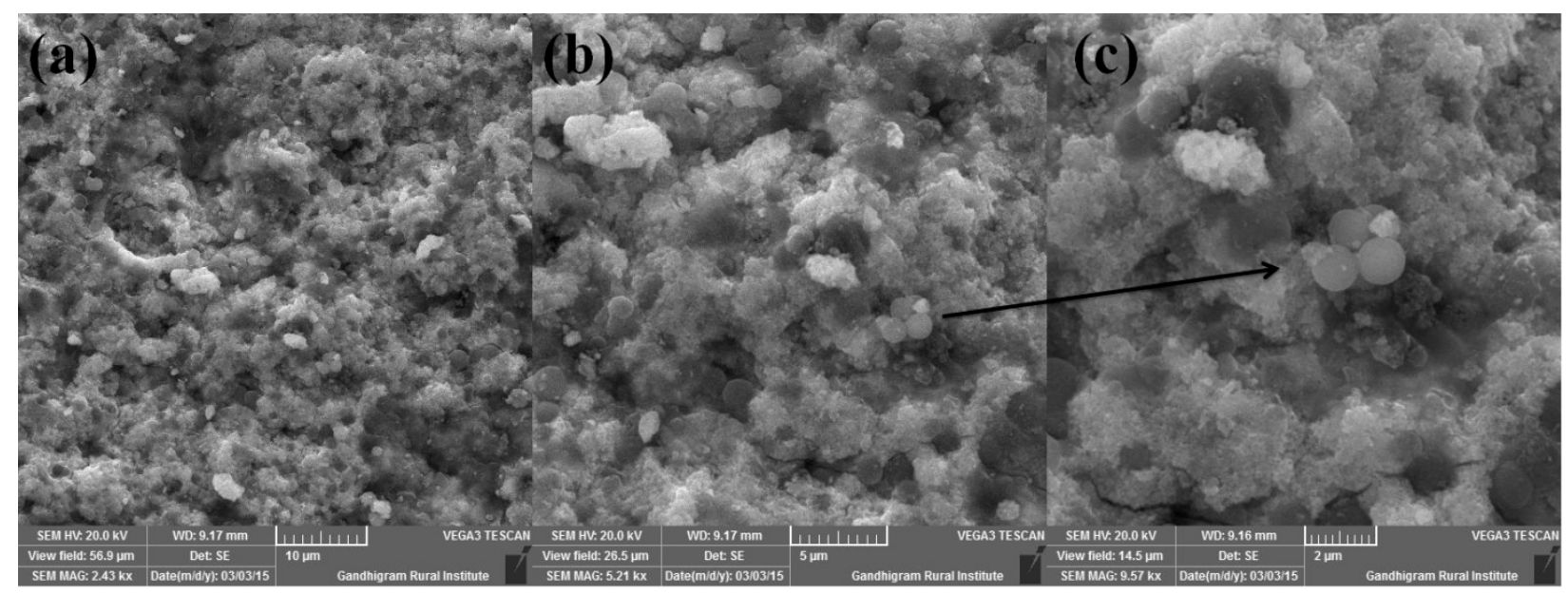

Figure 4. SEM micrographs of as synthesized Ag nanoparticles at different magnifications (a) $10 \mu \mathrm{M}$, (b) $1 \mu \mathrm{M}$, and (c) $2 \mu \mathrm{M}$.

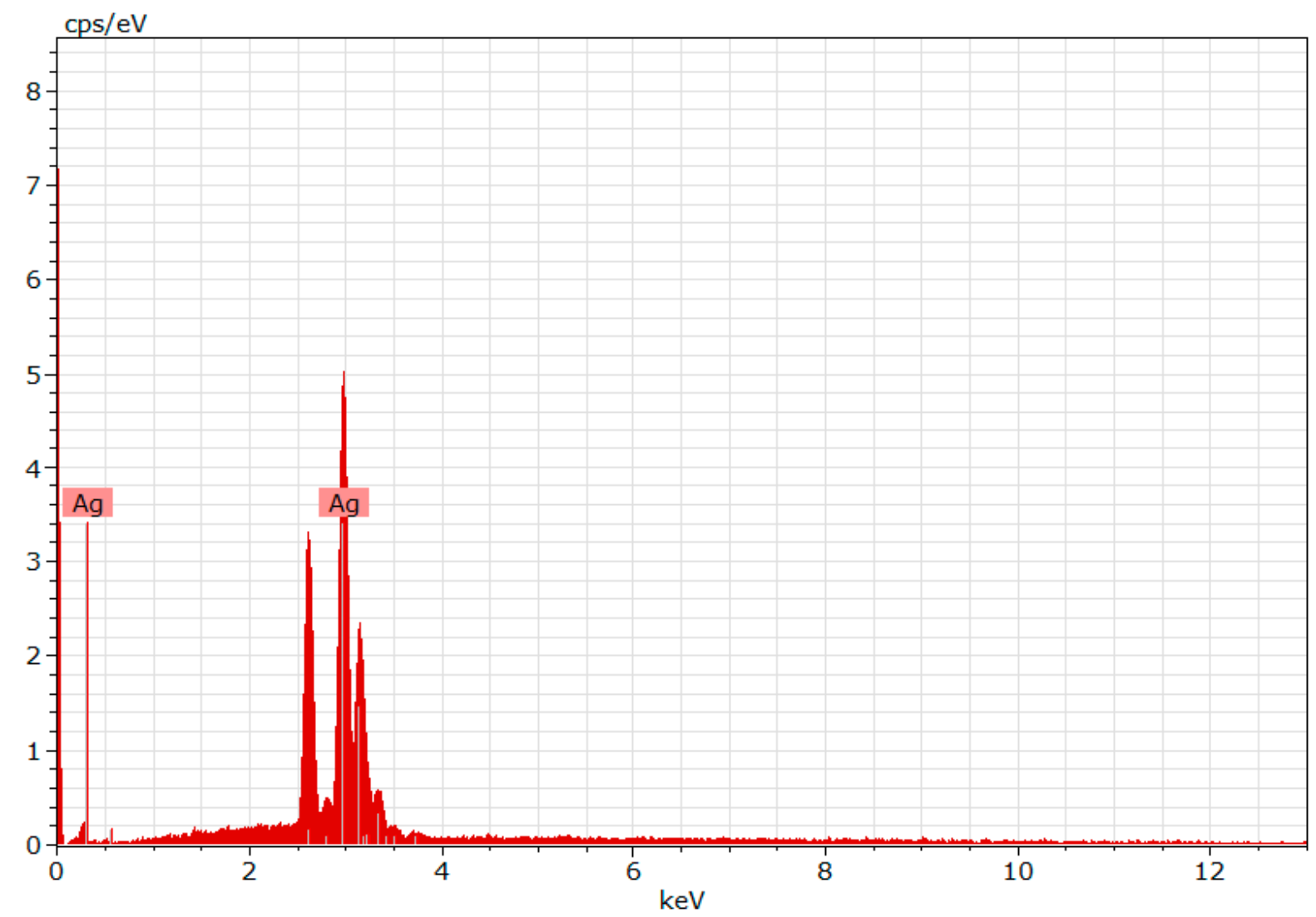

Figure 5. EDX spectrum of as synthesized Ag nanoparticles at different magnifications.

From the TEM images, the particle size histogram was drawn and shown as Figure 7. Figure 7 shows the mean size distribution of Ag NPs. The particle size ranges from 200 to $250 \mathrm{~nm}$ and the median diameter was $211 \mathrm{~nm}$ which showed the broader distribution of particles. 


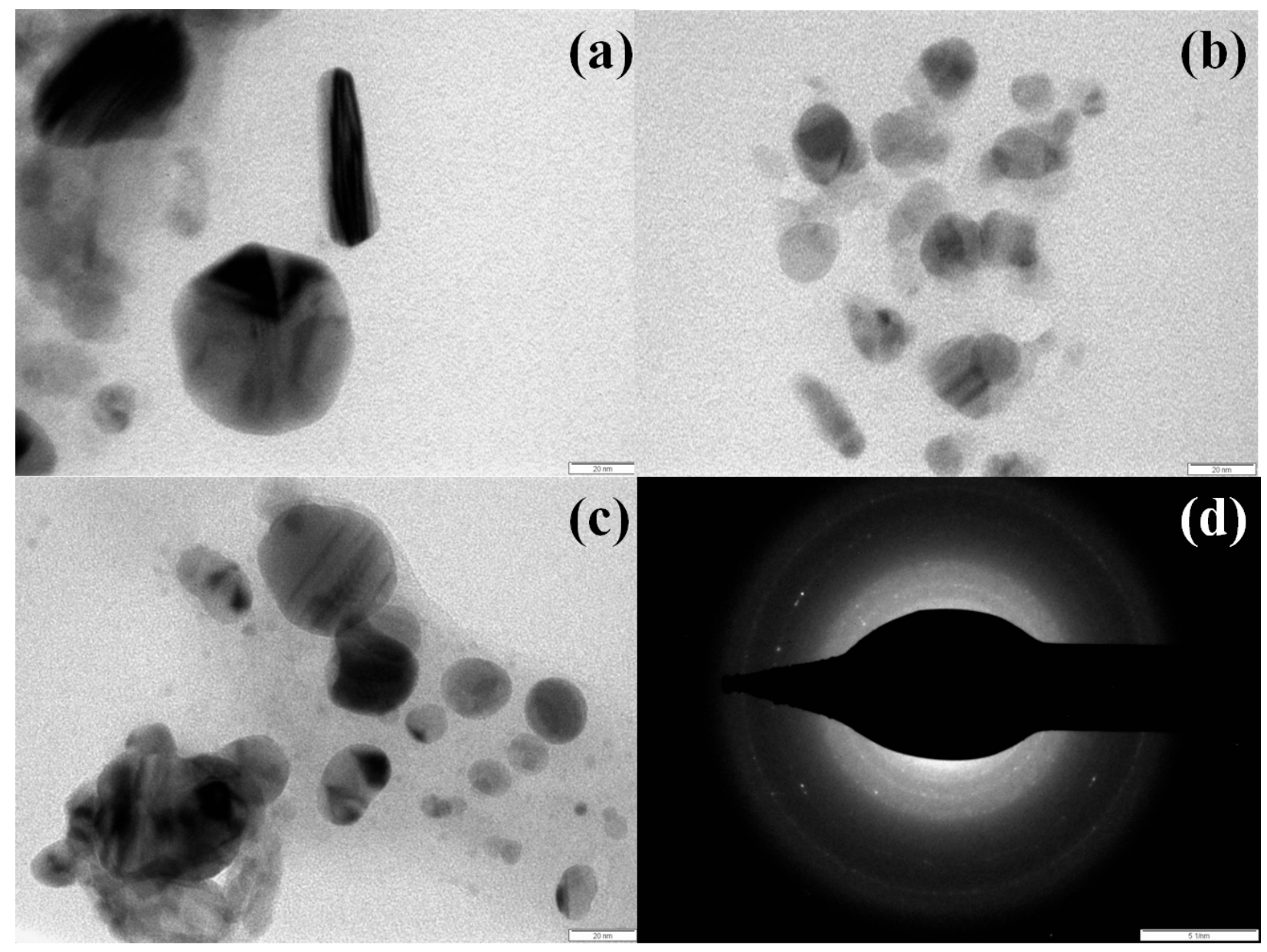

Figure 6. (a-c) TEM images of as synthesized Ag nanoparticles and (d) SAED pattern of Ag nanoparticles.

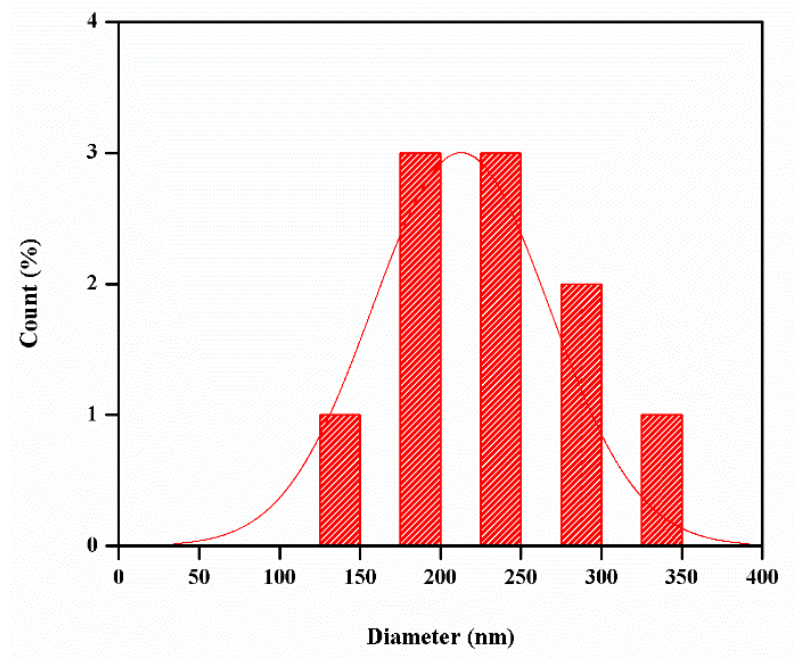

Figure 7. Particle size distribution analysis.

\subsection{Photocatalytic Efficiency of the Ag NPs}

The photocatalytic activity for the synthesized Ag NPs was monitored using MO dye solution, a pollutant that causes toxicity to the environment. The metal catalyst under irradiation of solar light has the better capability of degrading methyl orange dye [25]. In total, $50 \mathrm{mg}$ of synthesized Ag NPs was used as the photocatalyst for the degradation of $100 \mathrm{~mL}, 10 \mathrm{ppm}$ aqueous MO dye solution. The reaction was exposed under visible light 
irradiation for different time intervals and the UV-Vis absorption spectrum was observed which is shown in Figure 8a. The absorption peak for MO was perceived at $465 \mathrm{~nm}$. At varying time intervals during irradiation, absorption decreased and reached nearly zero showing the efficiency of the synthesized Ag NPs that performed as a catalyst. In order to prove the catalytic efficiency of silver nanoparticles, photocatalytic degradation of methyl orange in the presence of silver nanoparticles and absence of silver nanoparticles was also performed. Figure $8 \mathrm{~b}$ shows that there was no dye degradation observed in absence of catalyst and in the dark too, i.e., for degradation of methyl orange, light, as well as catalysts, is necessary for the fruitful photodegradation of pollutant.

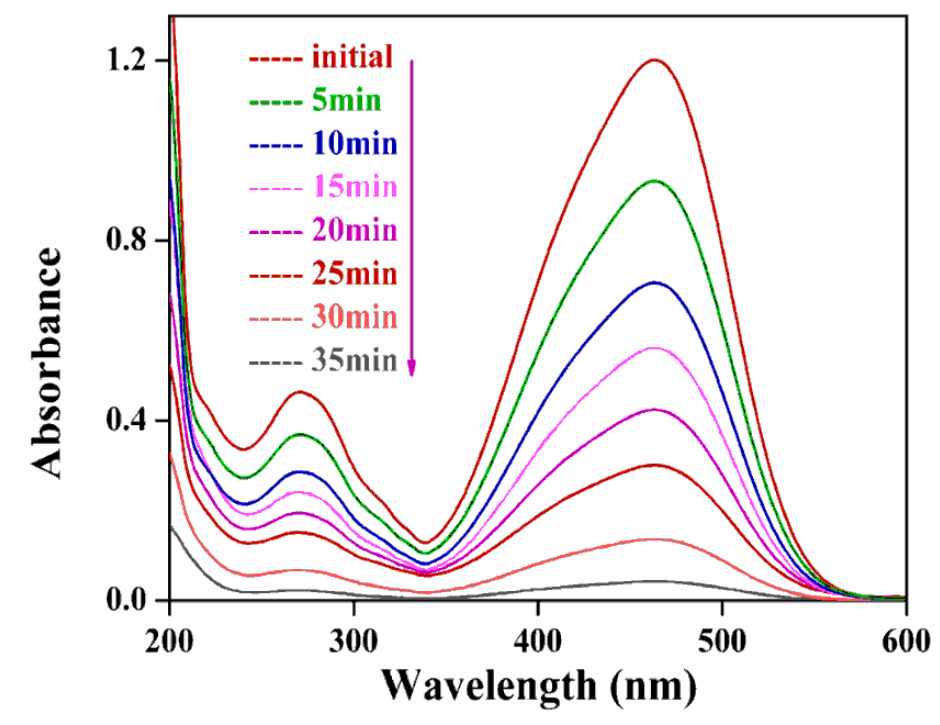

(a)

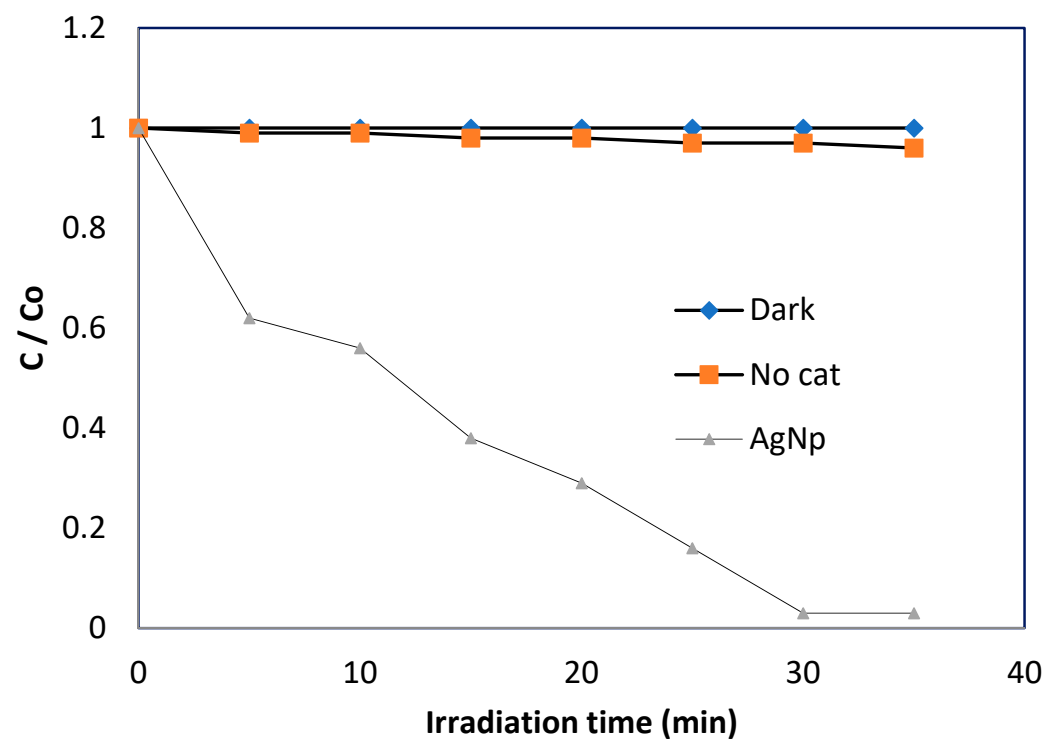

(b)

Figure 8. (a) Absorption of $\mathrm{MO}$ dye solution under visible light irradiation in the presence of synthesized Ag NPs. (b) Photocatalytic degradation of MO dye solution under visible light irradiation in the presence of synthesized Ag NPs. 
The effect of the photocatalyst dose for the degradation $\mathrm{MO}$ pollutant was scrutinized by different loading from 10 to $75 \mathrm{mg}$ which is shown in Figure 9a. The photodegradation activity of $50 \mathrm{mg}$ catalyst dose produced a greater number of active sites, accelerating the removal of MO efficiency. At higher dosage, catalyst would induce agglomeration of particles and turbid solution which restricts the ROS production in the reaction system. The effect of initial MO concentration was investigated by various concentrations ranging from 5 to $20 \mathrm{ppm}$ and the result is illustrated in Figure $9 \mathrm{~b}$. When using low concentration MO, only $85 \%$ of $\mathrm{MO}$ can be degraded under visible light irradiation after $35 \mathrm{~min}$. By increasing the high concentration, a greater number of $\mathrm{MO}$ molecules reaches the photo catalyst surface. Whereas, the degradation efficiency decreased because of light penetration reaching the surface of the catalyst, producing more mineralized products and then hindering the formation of oxidative radicals.
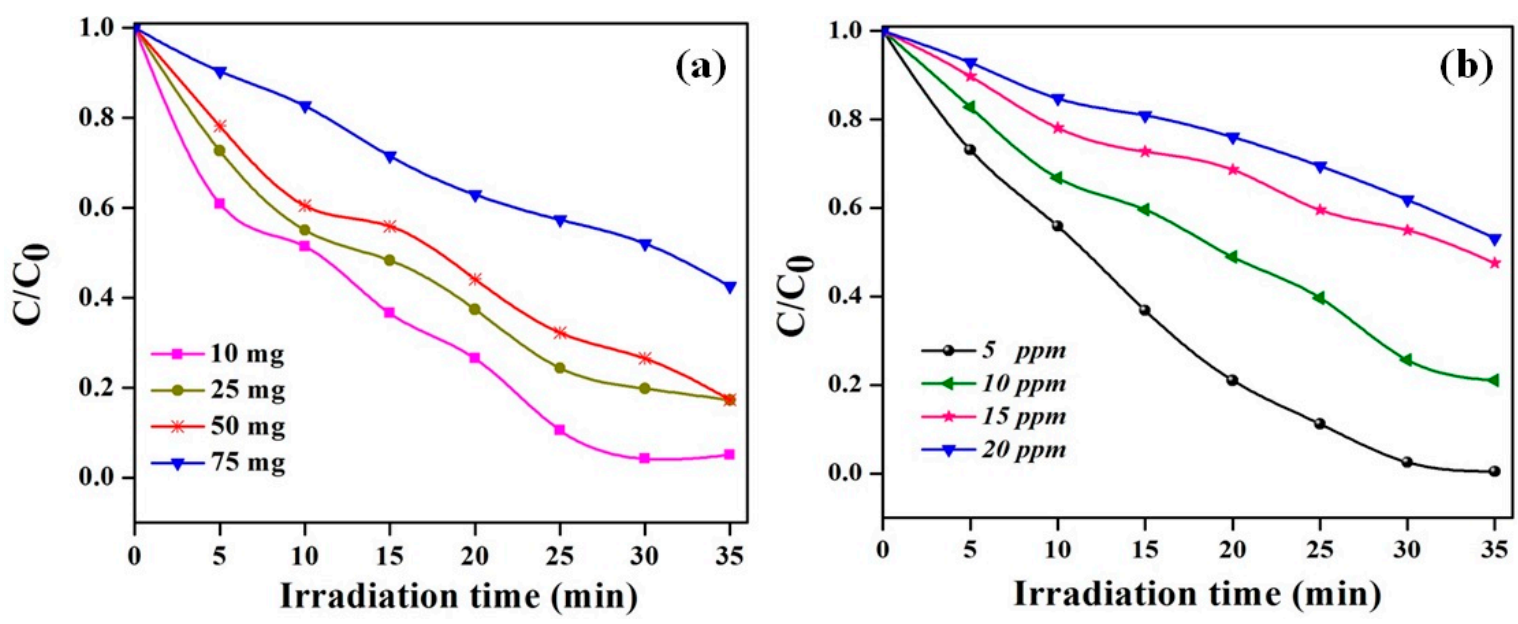

Figure 9. (a) Photodegradation of MO dye solution with different photocatalyst dosages (10-75 mg); (b) effect of different catalyst weights on the photodegradation of MO dye solution.

The $\mathrm{pH}$ value of the reaction system was evaluated to extend the practical applications of the photocatalyst and the photodegradation of the organic pollutants at various $\mathrm{pH}$ values as shown in Figure 10. The $\mathrm{pH}$ of the organic pollutants was varied from 2 to 10 using $\mathrm{HCl}$ and $\mathrm{NaOH}$ solutions. Meanwhile, the photocatalytic efficiency was increased at higher $\mathrm{pH}$, hindering the generation of more $\mathrm{OH}$ radicals produced by the basic condition [26]. However, the photocatalytic efficiency was established to be higher at basic and neutral $\mathrm{pH}$ values when compared to the acidic $\mathrm{pH}$ ranges. The results of statistical investigation reveal that the neutral $\mathrm{pH}$ has a significant impact on the photocatalytic activity, but it was $\mathrm{Ag} /$ plant at higher $\mathrm{pH}$ ranges that significantly assisted the degradation of basic pH condition.

\subsection{Antimicrobial Activity for Silver Nanoparticles}

Ag was known for its antimicrobial potential and it was supposed that the Ag NPs exert higher inhibition against various pathogens. The Ag NPs experience shapes reliant interactions with few pathogens. The interfaces of Ag NPs with biosystems are presented to be implicit and these particles are gradually being used as microbicidal agents. Ag NPs have the ability to destroy the pathogens which mainly relates to size, shape and concentration of the synthesized nanoparticles. Most of the report shows that the activity is strongly dependent on the size compared to the shape and concentration [27]. The surface of the pathogens physically interacts with the Ag NPs. At present, we are unable to give an estimation of how the surface areas of different NPs influence the killing activity or to relate the bacterial killing capacity of Ag NPs with their effective surface areas and our results provide a basis for the measurements of shape dependent bacterial activity of Ag NPs [28]. There was a strong interaction between S-H bonds of proteins in the plant 
extracts leading to inactivation. The antimicrobial activity was carried out using Agar diffusion method. In this work both the fungal (Candida albicans), Gram positive bacterial pathogens (Staphylococcus aureus, Streptococcus sp. and Bacillus subtilis) and Gram negative bacterial pathogens (E. coli, Klebsiella pneumoniae, Pseudomonas aeruginosa) were assisted as experimental microorganisms depicted in Figure 11. The nutrient broth was prepared and pure culture was plated using sterile rods. The biosynthesized Ag NPs, the plant extract, the Ag solution and the streptomycin acting as a positive control were loaded in each plate. The plates were incubated at $37^{\circ} \mathrm{C}$ for 1 day. The zone of incubation was measured in $\mathrm{mm}$ which shows a maximum zone of inhibition for B. subtilis when compared to other pathogens which is shown in Figure 12. The fungal strain also shows a significant antimicrobial activity against the synthesized Ag NPs. Therefore, the antimicrobial activity corresponds to a considerable progression in the nanomaterials field, with realistic applications.



Figure 10. Photodegradation of MO dye solution with different $\mathrm{pH}$ values (2-10).

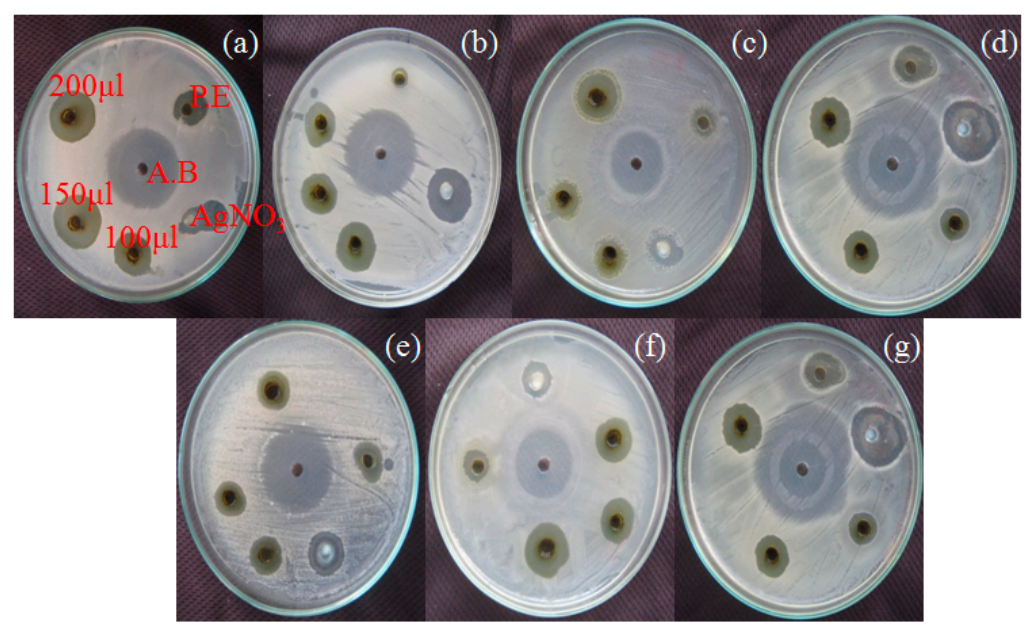

Figure 11. Zone inhibition of different pathogens by Ag NPs synthesized at $1 \mathrm{mM}$ concentration. (a) Bacillus subtillis, (b) Candida albicans, (c) E. Coli, (d) Klebsella pneumonia, (e) Psedomonaus arginosa, (f) Sapylococus Aures, (g) Streptococs faecalls. 


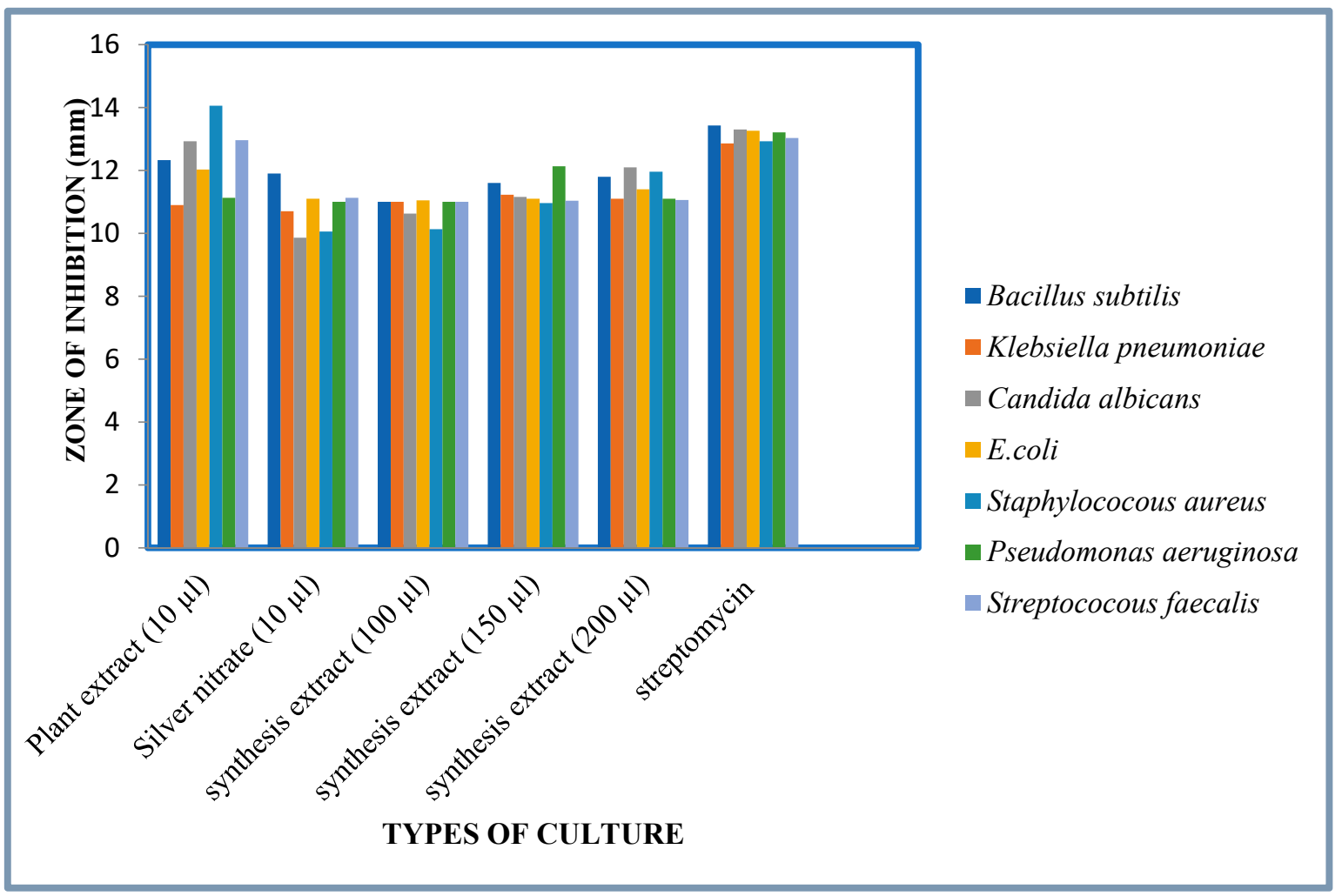

Figure 12. Antimicrobial activity of different pathogens using as synthesized Ag NPs.

\section{Conclusions}

An eco-friendly and cost effective protocol for the synthesis of Ag NPs using Alstonia scholaris (L.) R. Br. leaf extract at room temperature was described. Compared to other methods, the biomolecules in the leaf extract act as reducing and capping agents resulting in the reduction of, and further leading to the formation of, NPs. This scheme is hasty, effortless, economic and completely green. The extracellular synthesized Ag NPs were created, and these nanoparticles act as a probable candidate in the field of medicine. It is deduced that the phyto chemicals present in the leaf extract are responsible for capping the $\mathrm{Ag}$ NPs as indicated from FTIR. The Ag NPs have an average crystalline size of $16.57 \mathrm{~nm}$ and show an adequate stability and crystallinity. The synthesized Ag NPs also showed better, highly efficient and stable photocatalyst under visible light illumination. Within $35 \mathrm{~min}$, methyl orange dye was nearly $98 \%$ degraded by silver nanoparticles which revealed that the Ag NPs play dual applications in the present work. The results addressed herein showed the antimicrobial activities against various pathogens of synthesized Ag NPs which has tremendous scope in the field of medicine.

Author Contributions: J.S.: Synthesis, characterization and antimicrobial studies, Manuscript preparation, P.S.K.; Photocatalytic activity, Manuscript preparation; S.K.; supervision, project administration, funding acquisition, Review and editing of manuscript. All authors have read and agreed to the published version of the manuscript.

Funding: This research received no external funding.

Acknowledgments: The authors express their sincere thanks to the College managing board, Principal and Head of the Department, VHNSN College for providing necessary research facilities. We thank the Gandhigram Deemed University, Dindigul for SEM image observation and CECRI, Karaikudi for XRD study. The authors also acknowledge DST-SAIF for providing TEM facility.

Conflicts of Interest: The authors declare no conflict of interest. 


\section{References}

1. Kasthuri, J.; Kathiravan, K.; Rajendiran, N.J. Phyllanthin-assisted biosynthesis of silver and gold nanoparticles: A novel biological approach. Nanoparticle Res. 2009, 11, 1075. [CrossRef]

2. Narayanan, R.; El-Sayed, M.A. Shape-Dependent Catalytic Activity of Platinum Nanoparticles in Colloidal Solution. Nano Lett. 2004, 4, 1343. [CrossRef]

3. Gomez-Romero, P. Hybrid Organic-Inorganic Materials-In Search of Synergic Activity. Adv. Mater. 2001, 13, 163. [CrossRef]

4. Ajitha, B.; Ashok Kumar Reddy, Y.; Sreedhara Reddy, P. Green synthesis and characterization of silver nanoparticles using Lantana camara leaf extract. Mater. Sci. Eng. C 2015, 49, 373. [CrossRef]

5. Masurkar, S.A.; Chaudhari, P.R.; Shidore, V.B.; Kamble, S.P. Rapid Biosynthesis of Silver Nanoparticles Using Cymbopogan Citratus (Lemongrass) and its Antimicrobial Activity. Nano-Micro Lett. 2011, 3, 189. [CrossRef]

6. Kouvaris, P.; Delimitis, A.; Zaspalis, V.; Papadopoulos, D.; Sofia, A.T.; Michailidisa, N. Green synthesis and characterization of silver nanoparticles produced using Arbutus Unedo leaf extract. Mater. Lett. 2012, 76, 18. [CrossRef]

7. Guidelli, E.J.; Ramos, A.P.; Zaniquelli, M.E.D.; Bajja, O. Green synthesis of colloidal silver nanoparticles using natural rubber latex extracted from Hevea brasiliensis. Spectrochim. Acta Part A Mol. Biomol. Spectrosc. 2011, 82, 140. [CrossRef] [PubMed]

8. Ahmad, N.; Sharma, S. Green Synthesis of Silver Nanoparticles Using Extracts of Ananas comosus. Green Chem. $2012,2,141$.

9. Tran, Q.H.; Nguyen, V.Q.; LE, A.T. Corrigendum: Silver nanoparticles: Synthesis, properties, toxicology, applications and perspectives. Adv. Nat. Sci. Nanotechnol. 2013, 4, 033001. [CrossRef]

10. Jeeva, K.; Thiyagarajan, M.; Elangovan, V.; Geetha, N.; Venkatachalam, P. Caesalpinia coriaria leaf extracts mediated biosynthesis of metallic silver nanoparticles and their antibacterial activity against clinically isolated pathogens. Ind. Crop. Prod. 2014, 52, 714. [CrossRef]

11. Sharma, V.K.; Yngard, R.A.; Lin, Y. Silver nanoparticles: Green synthesis and their antimicrobial activities. Adv. Colloid Interface Sci. 2009, 145, 83. [CrossRef]

12. Prasad, K.S.; Pathak, D.; Patel, A.; Dalwadi, P.; Prasad, R.; Patel, P.; Selvaraj, K. Biogenic synthesis of silver nanoparticles using Nicotiana tobaccum leaf extract and study of their antibacterial effect. Afr. J. Biotechnol. 2011, 10, 8122.

13. Rajeswari, A.; Sujatha, D.; Balasaraswathi, K.; Mani, U.; Chellan, R.; Asit Baran, M. Phytosynthesis of silver nanoparticles using Coccinia grandis leaf extract and its application in the photocatalytic degradation. Colloids Surf. B Biointerfaces 2012, 94, 226.

14. Jiang, H.; Manolache, S.; Wong, A.C.L.; Denes, F.S. Plasma-enhanced deposition of silver nanoparticles onto polymer and metal surfaces for the generation of antimicrobial characteristics. J. Appl. Polym. Sci. 2004, 93, 1411. [CrossRef]

15. Prabhu, S.; Poulose, E.K. Silver nanoparticles: Mechanism of antimicrobial action, synthesis, medical applications, and toxicity effects. Int. Nano Lett. 2012, 2, 32. [CrossRef]

16. Douglas, T.; Young, M. Host-guest encapsulation of materials by assembled virus protein cages. Nature 1998, 393, 152. [CrossRef]

17. Mourato, A.; Gadanho, M.; Lino, A.R.; Tenriro, R. Biosynthesis of Crystalline Silver and Gold Nanoparticles by Extremophilic Yeasts. Bioinorg. Chem. Appl. 2011, 2011, 546074. [CrossRef] [PubMed]

18. Nithya, R.; Ragunathan, R. Synthesis of silver nanoparticle using pleurotus sajor caju and its antimicrobial activity study. Dig. J. Nanomater. Biostructures 2009, 4, 623.

19. Sulaiman, G.M.; Mohammed, W.H.; Marzoog, T.R.; Abdul Amir AlAmiery, A.; Kadhum, A.A.H.; Mohamad, A.B. Green synthesis, antimicrobial and cytotoxic effects of silver nanoparticles using Eucalyptus chapmaniana leaves extract. Asian Pac. J. Trop. Biomed. 2013, 3, 58. [CrossRef]

20. Li, S.; Shen, Y.; Xie, A.; Yu, X.; Qiu, V.; Zhang, L.; Zhang, Q. Green synthesis of silver nanoparticles using Capsicum annuum L. extract. Green Chem. 2007, 9, 852. [CrossRef]

21. Noginov, M.A.; Zhu, G.; Bahoura, M.; Adegoke, J.; Smal, C.; Ritzo, B.A.; Drachev, V.P.; Shalaev, V.M. The effect of gain and absorption on surface plasmons in metal nanoparticles. Appl. Phys. B 2007, 86, 455. [CrossRef]

22. Amarendra, D.D.; Krishna, G. Biosynthesis of silver and gold nanoparticles using Chenopodium album leaf extract. Colloids Surfaces. A Physicochem. Eng. Asp. 2010, 369, 27.

23. Philip, D. Mangifera Indica leaf-assisted biosynthesis of well-dispersed silver nanoparticles. Spectrochim. Acta Part A Mol. Biomol. Spectrosc. 2011, 78, 327. [CrossRef]

24. HimakshiBhati, K.; Malik, C.P. Biosynthesis of silver nanoparticles using fresh extracts of Tridax Procumbens Linn. Indian J. Exp. Biol. B 2014, 52, 359.

25. Garcia, M.A. Surface plasmons in metallic nanoparticles: Fundamentals and applications. J. Phys. D Appl. Phys. 2011, 28, 44. [CrossRef]

26. Prakash, K.; Vinoth Kumar, J.; Latha, P.; SenthilKumar, P.; Karuthapandian, S. Fruitful fabrication of CDs on GO/g-C3N4 sheets layers: A carbon amalgamation for the remediation of carcinogenic pollutants. J. Photochem. Photobiol. A 2019, 370, 94. [CrossRef]

27. Vasudeva Reddy, N.; Venkata Subbaiah, K.; Venkateswarlu, N.; Pushpalatha, B.; Sukhendu Bikash, G.; Vijaya, T. First report of biomimetic synthesis of silver nanoparticles using aqueous callus extract of Centella asiatica and their antimicrobial activity. Appl. Nanosci. 2015, 5, 801.

28. Choi, O.; Hu, Z. Size dependent and reactive oxygen species related nanosilver toxicity to nitrifying bacteria. Environ. Sci. Technol. 2008, 42, 4583. [CrossRef] 